\title{
Protecting the central nervous system during ischemia: A difficult task
}

John A. Kern, MD

See related article on page 1331 .

From the University VA Health Sciences Center, Department of Cardiothoracic Surgery, Charlottesville, Va.

Received for publication Oct 31, 2005; accepted for publication Nov 1, 2005.

Address for reprints: John A. Kern, MD, University VA Health Sciences Center, Department of Cardiothoracic Surgery, Box 310-88, Charlottesville, VA 22908 (E-mail: jkern@ virginia.edu; JAK3R@virginia.edu).

J Thorac Cardiovasc Surg 2006;131:1226

$0022-5223 / \$ 32.00$

Copyright $\odot 2006$ by The American Association for Thoracic Surgery

doi:10.1016/j.jtcvs.2005.11.054
卫 his issue contains a remarkable study by Kawata and colleagues. ${ }^{1}$ The prevention of central nervous system (CNS) damage during prolonged hypothermic circulatory arrest has significant ramifications. In this study the authors demonstrated that erythropoietin (EPO) crosses the blood brain barrier and protects the brain and spinal cord from prolonged ischemic injury during hypothermic circulatory arrest. The fact that the animals in this study were kept under hypothermic circulatory arrest for 120 minutes is simply astounding. The use of EPO for CNS protection during cold ischemia is a novel concept. However, the exact mechanism needs to be elucidated. Because EPO is already used in humans, and safety and efficacy data are already known, a clinical trial could be easily established.

This study has limitations. Only 5 animals were used in each of the EPO and control groups. In addition, the animals were never fully allowed to recover and were always kept intubated and anesthetized during the recovery and neurologic assessment period. Even with the modification of the neurologic scoring system to allow for this, I have grave reservations about how accurately the animals' neurologic status could be evaluated. One cannot argue with the results of the histologic analyses and the evaluation of the brain, spinal cord, and cerebrospinal fluid, and it seems as though EPO does have direct protective effects on the CNS. Whether these beneficial effects are long-lasting needs to be elucidated through chronic studies. Also, although many drugs have proven beneficial in protecting the brain and spinal cord during ischemia in experimental animal models, none have proven particularly beneficial in humans.

Although the results of this study are remarkable and give us reason to be excited, we must temper our enthusiasm with the reality that this is but one study in a very small group of animals that were evaluated (while anesthetized and intubated) for only 12 hours postoperatively. Clearly, more work needs to be done.

\section{Reference}

1. Kawata M, Takamoto S, Kitahoi K, Tsukihara H, Morota T, Ono M, et al. Erythropoietin protects the central nervous system during prolonged hypothermic circulatory arrest: An experimental study in a canine model.

\section{Notice of Retraction}

Dent CL, Spaeth JP, Jones BV, et al. Brain magnetic resonance imaging abnormalities after the Norwood procedure using regional cerebral perfusion. J Thor Cardiovasc Surg 2006;131:190-197. This article has been retracted by the Publisher.

Due to an administrative error in production, it was published twice-in the December 2005 issue (J Thor Cardiovasc Surg 2005;130:1523-1530) and in the January 2006 issue (J Thor Cardiovasc Surg 2006;131:190-197). The article has been retracted from the January 2006 issue. The version of record can be found in the December 2005 issue (J Thor Cardiovasc Surg 2005;130:1523-1530). 